\title{
Designing a Simulation for Student Evaluation Using Scriven's Key Evaluation Checklist
}

Shelly Jensen Reed

Brigham Young University - Provo, shelly-reed@byu.edu

Follow this and additional works at: https://scholarsarchive.byu.edu/facpub

Part of the Other Nursing Commons

\section{Original Publication Citation}

Reed, S. J. (2010). Designing a simulation for student evaluation using Scriven's Key Evaluation Checklist. Clinical Simulation in Nursing, 6, 41-44.

\section{BYU ScholarsArchive Citation}

Reed, Shelly Jensen, "Designing a Simulation for Student Evaluation Using Scriven's Key Evaluation Checklist" (2009). Faculty Publications. 5320.

https://scholarsarchive.byu.edu/facpub/5320 


\title{
Designing a Simulation for Student Evaluation Using Scriven's Key Evaluation Checklist
}

\author{
Shelly J. Reed, MSN, APRN
}

Brigham Young University College of Nursing, Provo, UT 84602, USA

\section{KEYWORDS}

simulation;

evaluation;

Scriven's Key Evalua-

tion Checklist;

student competency

\begin{abstract}
Human patient simulation use has increased dramatically in nursing education over the past 10 years, with many benefits. One advantage is that it allows students to learn by practicing skills in a risk-free environment, with immediate faculty feedback. Another benefit is that it prepares and ensures the competence of student nurses, leading to improved patient safety outcomes. Student opinions gathered in a survey of nursing schools and simulator centers favored use of competency evaluation using simulation in at least some circumstances. As little research concerning use of simulation to evaluate student competency can be found, an established guide such as Scriven's Key Evaluation Checklist can provide a solid backbone for nursing faculty designing a simulation for student evaluation. This checklist contains 18 checkpoints that help the nurse educator to comprehensively plan, design, implement, and evaluate an evaluative simulation.
\end{abstract}

Cite this article: Reed, S. (2010, March). Designing a simulation for student evaluation using Scriven's Key Evaluation Checklist. Clinical Simulation in Nursing, VOL(6), e41-e44. Doi: 10.1016/j.ecns.2009.03.121.

(C) 2010 Published by Elsevier Inc. on behalf of the International Nursing Association for Clinical Simulation and Learning.

\section{Background}

Use of human patient simulation has increased dramatically in nursing education over the past 10 years, providing many benefits. Simulation allows use of structured clinical experiences that may not be encountered in a clinical rotation (Nehring, Ellis, \& Lashley, 2001). Simulator availability and realism have improved, with more availability to the nurse learner (Bremner, Aduddell, Bennett, \& VanGeest, 2006). Simulation allows students to critically reflect on and analyze their own actions and the clinical decision making of others (Jeffries, 2007). The use of higher-level technology allows hands-on,

E-mail address: shelly-reed@byu.edu (S. J. Reed). active participation in realistic scenarios and a degree of realism vital for training. Cognitive, technical, and behavioral skills can be improved, training costs can be reduced through concentrated learning experiences, and a wide variety of simulated patient-care experiences can be provided (Yaeger et al., 2004). Multiple learning objectives can be taught in a realistic environment without patient risk (Wilford \& Doyle, 2006). Another benefit is to prepare and ensure the competence of student nurses, which leads to improved patient safety outcomes (Nehring \& Lashley, 2004; Radhakrishnan, Roche, \& Cunningham, 2007).

There is limited research in the use of simulation in nursing education and the evaluation of student competency. In a survey of nursing schools and simulation centers, Nehring 
and Lashley (2004) gathered student opinions about competency evaluation using simulation. Three fourths of students in responding programs reported that competency evaluation using simulation was appropriate in at least some circumstances. Universities used simulation for competency

\section{Key Points}

- Use of simulation to evaluate student performance provides many possibilities.

- Scriven's Key Evaluation Checklist provides the structure for planning an evaluation

- Evaluation with simulation may more closely approximate real world performance than traditional examination methods evaluation more often than community colleges did. Faculty evaluation of student performance was found to be the primary evaluation method, with student report of performance second and evaluation of videotaped performance third (Nehring \& Lashley, 2004). Radhakrishnan et al. (2007) described using simulation to evaluate clinical skill performance in several areas: safety, basic assessment, prioritization, problem-focused assessment, ensuing interventions, delegation, and communication. Their pilot study, conducted with nursing students, used a performance-rating tool measuring clinical performance improvement. Students who practiced using simulation scored higher in performance rating than the group using clinical training alone with some identified skills. Additional studies were recommended.

\section{Scriven's Key Evaluation Checklist}

Use of simulation in nursing education is rapidly expanding. With little available evidence about the use of simulation for student evaluation, an established guide such as Michael Scriven's Key Evaluation Checklist (KEC) has the potential to provide educators with a solid guiding framework. Scriven, past president of both the American Evaluation Association and the American Educational Research Association, has published more than 400 articles in many areas, including evaluation (Claremont Graduate University, 2009). Scriven's KEC is also well known for contributing to evaluation methodology. As the KEC is evaluation specific rather than discipline specific, it has a multidisciplinary focus and can be used in many areas, such as project evaluation and performance appraisal (Davidson, 2005). The KEC provides a useful and established guide for the nurse educator designing an evaluation of student performance using simulation.

Many evaluation checklists incorporate a complex theory or at least a set of assumptions. Scriven's KEC (Figure 1) consists of checkpoints representing "layers" in an evaluation. It is weakly sequential, meaning that it encourages repeated checkpoint review, which sometimes leads to modification
Scriven's model.

\begin{tabular}{|l|l|}
\hline Preliminaries & I. Executive Summary \\
& II. Preface \\
& III. Methodology \\
\hline Foundations & 1. Background and Context \\
& 2. Descriptions and Definitions \\
& 3. Consumers \\
& 4. Resources \\
& 5. Values \\
\hline Sub-Evaluations & 6. Process Evaluation \\
& 7. Outcome Evaluation \\
& 8. \& 9.Comparative Cost-Effectiveness \\
& 10. Exportability \\
& 11. Overall Significance \\
\hline Conclusions & 12. Recommendations and Explanations \\
& 13. Responsibilities \\
& 14. Reporting and Follow-up \\
& 15. Meta-Evaluation \\
\hline
\end{tabular}

Note.Used with permission of E. Jane Davidson and Michael Scriven.

Figure 1 Scriven's model.

of earlier checkpoints (Scriven, 2007b). The effect of repeating or reviewing checkpoints creates a dynamic, rather than a static, model. The checklist consists of three preliminary checkpoints and 15 subsequent checkpoints grouped into the categories of foundations, sub-evaluations, and conclusions. These checkpoints provide focus for creating, structuring, and evaluating evaluations of any kind. The checklist user employs his or her own discretion and judgment in using the checklist (Davidson, 2005; Scriven, 2007a).

\section{Use of the Checklist When Designing a Simu- lation for Evaluation}

Davidson (2005) described the first preliminary step in Scriven's KEC as the executive summary. This step clarifies what is going to be evaluated and how. The executive summary includes descriptions and definitions (also a later checkpoint) to help identify the student's current level, as well as where he or she should be. When the checklist is used for student evaluation, the descriptions-and-definitions checkpoint would include how simulation is currently being used in the nursing program, the student's prior exposure to simulation, and whether the student has prior evaluation history with simulation. Scriven's preface checkpoint of the KEC describes the big picture for the evaluation, that is, the purpose of the evaluation and the main evaluation questions (Davidson, 2005). Examples of big-picture questions might include: Is the simulation to determine whether a student is progressing adequately during the semester? Is the simulation to determine skill proficiency? Is it to show efficient teamwork? and Is it to determine whether a student should move from one level to the next? The final preliminary step includes the methodology checkpoint, or simulation design. In this case, it is the experiential evaluation provided by simulation, one based on student performance. Formative evaluation (evaluation for the purpose of improvement) and summative evaluation (deciding whether the student (the evaluee) has mastered level objectives) are 
two examples of evaluation design. The nurse educator needs to decide which design will answer the big-picture question.

The foundations portion of the KEC provides the blueprint. The background and context and descriptions and definitions steps identify the nursing student in detail. For example, where should the student be at this point? What nursing behaviors should the student be able to exhibit? Objectives and purpose of the evaluation would also be included here. The educator should evaluate available resources, such as type of simulator or simulation to be used for the evaluative simulation. For example, there are simulators available that can provide objective evidence of performance using built-in recording capabilities (Good, 2003). The educator needs to question what simulator would be appropriate for the intended evaluation. Does the scenario require a high-fidelity human patient simulator? Will a low-fidelity simulator work in this situation? Would a computer-based simulation be appropriate? Are appropriate scripted and designed simulations already available to answer the big-picture questions? Is the chosen simulator readily accessible, or will the simulator have to be reserved, borrowed, or rented? Is there a cost? Will this cost be covered by the scholastic institution, by outside funding, or by the student? Will there be costs associated with simulator maintenance, faculty release time, faculty development, and faculty buy-in? These resource questions also help to determine whether simulation is a cost-effective evaluative method.

Cost-effectiveness is only one factor one should considerer when researching simulation as a form of student evaluation. Additional criteria include consumers, or those who might be affected by the evaluee; values, which concern the integrity of the evaluation; process evaluation, when the student is evaluated using simulation; and outcome evaluation (Davidson, 2005).

Consumers affected by the evaluee include patients, their families, and their communities. Additional consumers include a student's future employer, the student's school, and the instructors, as all are affected by successful or unsuccessful students.

Value and effectiveness of the simulation used for evaluative purposes are also important. Where were the criteria to be used in the evaluation obtained? Are important skills to be evaluated? How will competent performance be evaluated? These questions help to determine the value of using simulation for evaluation. Grading rubrics are also helpful to preserve value.

Process evaluation defines the strength of the simulation design, as well as the delivery (Davidson, 2005). Process evaluation contains the following four elements of a wellplanned simulation: scripting the simulation, staff development and student orientation, executing the simulation, and evaluation of the simulation (Jeffries, 2007). Scripting can be accomplished by using written scripts that are already available or scripts specifically formulated to answer the big-picture questions. A student competency evaluation might be based on a problem recognition task (see Figure 2) designed to evaluate problem-solving and diagnostic skills. Simulation is easily adapted to this format (Jeffries, 2007).

Outcome evaluation is another important evaluative criterion (Davidson, 2005). Is the outcome a skill performance or behavior? Is it verbalization of knowledge pertaining to a condition? Once the outcome has been identified, how will it be evaluated? Will it be a subjective evaluation by the session facilitator? Will there be a grading rubric for performance outcomes? Will the rubric identify

Example of Simulation Planning: Care of the client with postpartum hemorrhage.

1. Simulation scripting:
A scenario is adopted or developed to illustrate a situation in which a client is predisposed to a
postpartum hemorrhage.
Faculty members with expertise in the content area review the scenario.
2. Staff development and student orientation:
The scenario is run with faculty colleagues or a group of advanced students to see whether
agreement on the scenario choice is present. This run-through allows assessment of the difficulty
of the scenario and the time it will take to complete.
For an evaluative simulation, students should have prior exposure to simulation.
3. Composition of problem recognition form/rubric.
A problem recognition form also ties in closely with a grading rubric.
With this scenario, some examples might be,
"Student assesses the fundus of the uterus."
"Student provides a means to empty the client's bladder when the uterine fundus is displaced
above and to the right of the umbilicus."
"Student provides fundal massage for a boggy uterus."
Considerations when using simulation for evaluation would be to provide problem recognition
that answers the big-picture questions.
4. Simulation implementation.
Considerations in this phase include dimensions of merit, such as how many evaluees (nursing
students) will be involved in the evaluative simulation.

Figure 2 Simulation: Care of the client with postpartum hemorrhage. 
present or absent behaviors (Radhakrishnan et al., 2007)? Evaluation based on outcomes rather than goals allows evaluation teams to more easily identify all effects (Davidson, 2005). Grading rubrics can be helpful to determine whether desirable outcomes have been reached. Rubrics help to eliminate evaluator bias, rendering the evaluation more objective than subjective. Nursing students should be made aware of the outcomes on the rubric in advance so that they can study or prepare for the simulation used for evaluation as they would for any other exam (P. Ravert, personal communication, November 18, 2008).

Scriven's comparative cost-effectiveness checkpoint, as described by Davidson (2005), is important when one is considering simulation as an evaluative method in nursing education. Type, availability, and cost of simulation fall into this category. The cost of simulation compared with the cost of other evaluation methods should be considered. "Might another method of evaluation less costly provide a means of evaluation less costly or of similar or greater value? Are costs excessive, quite high, just acceptable, or very reasonable?" (Davidson, 2005, p. 24).

The criterion of exportability is especially pertinent when simulation is used for evaluative purposes in nursing education. Exportability describes the "elements such as an innovative design or approach which might make it potentially valuable or a significant contribution in another setting" (Davidson, 2005, p. 7). Using simulation to evaluate clinical skills would seem to provide more exportability to an actual clinical setting than many other commonly used forms of evaluation. Bremner et al. (2006) described many clinical advantages to using simulation, including simulated clinical scenarios providing real-world experiences without risk to patient or students. Exportability of the use of simulation for evaluation might provide the same advantages.

Once simulation is used for evaluation in nursing education, the following checkpoints from Scriven's KEC can be used to determine whether the simulation meets educational evaluation needs and where it is lacking. In addition to determining the overall significance of evaluation using simulation, other conclusions can be drawn. These include (a) recommendations and explanations (how the simulation went and how it could be improved), (b) responsibilities (who or what was responsible for good or bad results), and (c) reporting and follow-up (evaluation reporting and who receives the results). Meta-evaluation is the conclusion, providing a critical assessment of the strengths and weaknesses of the evaluation itself (Davidson, 2005). These checkpoints also provide the evaluation steps required for a good simulation as defined by Jeffries (2007).

Use of patient simulators is increasing in the education and training of health care professionals. Educational institutions indicate that the use of simulation to evaluate competency is appropriate under certain circumstances (Nehring \& Lashley, 2004). An established tool such as Scriven's KEC may provide the basis for a sound simulation design and may supply a means for drawing conclusions about the effectiveness of the process of using simulation to evaluate student competency.

\section{References}

Bremner, M. N., Aduddell, K., Bennett, D. N., \& Van Geest, J. B. (2006) The use of human patient simulators-best practices with novice nursing students. Nurse Educator, 31(4), 170-174.

Claremont Graduate University. (2009). Michael Scriven. Retrieved February 12, 2009, from www.cgu.edu/pages/4745.asp

Davidson, E. J. (2005). Evaluation methodology basics. Thousand Oaks, CA: Sage.

Jeffries, P. R. (2007). Simulation in nursing education: From conceptualization to evaluation. New York: National League for Nursing.

Nehring, W. M., Ellis, W. E., \& Lashley, F. R. (2001). Human patient simulator in nursing education: An overview. Simulation \& Gaming, 32, 194-204.

Nehring, W. M., \& Lashley, F. R. (2004). Current use and opinions regarding human patient simulators in nursing education: An international survey. Nursing Education Perspectives, 25(5), 244-248.

Radhakrishnan, K., Roche, J. P., \& Cunningham, H. (2007). Measuring clinical practice parameters with human patient simulation: A pilot study. International Journal of Nursing Education Scholarship, 4(1) 1-11.

Scriven, M. (2007a). Key Evaluation Checklist. Retrieved August 6, 2008, from www.wmich.edu/evalctr/checklists/kec_feb07.pdf

Scriven, M. (2007b). The logic and methodology of checklists. Retrieved August 6, 2008, from www.wmich.edu/evalctr/checklists/papers/ logic\&methodology_dec07.pdf

Wilford, A., \& Doyle, A. W. (2006). Integrating simulation training into the nursing curriculum. British Journal of Nursing, 15(11), 604-607.

Yaeger, K., Halamek, L., Coyle, M., Murphy, A., Anderson, J., Bouyle, K., et al. (2004). High fidelity simulation-based training in neonatal nursing. Advances in Neonatal Care, 4(6), 326-331. 